\title{
ARTIGO
}

dO https://doi.org/10.22481/praxis.v15i32.5048

\section{CLUBE DE CIÊNCIAS COMO UM ESPAÇO DE FORMAÇÃO: CONCEPÇÕES DE MONITORES SOBRE ENSINAR CIÊNCIAS}

\author{
SCIENCE CLUB AS A TRAINING SPACE: CONCEPTIONS OF MONITORS ON \\ TEACHING SCIENCES
}

\section{CLUB DE CIENCIAS COMO UN ESPACIO DE FORMACIÓN: CONCEPCIONES DE MONITORES SOBRE ENSEÑAR CIENCIAS}

\author{
Beatriz Garcia Lippert \\ Pontifícia Universidade Católica do Rio Grande do Sul - Brasil \\ Nathália Fogaça Albuquerque \\ Pontifícia Universidade Católica do Rio Grande do Sul - Brasil \\ Valderez Marina do Rosário Lima \\ Pontifícia Universidade Católica do Rio Grande do Sul - Brasil
}

\begin{abstract}
Resumo: A formação de professores de ciências é um assunto que clama por atenção. Um espaço possível para participação de licenciandos em ações docentes revigoradas é o Clube de Ciências, no qual estudantes de cursos de licenciatura podem atuar como monitores de atividades propostas a alunos da Educação Básica. O problema de pesquisa do presente artigo foi: De que forma experiências vivenciadas por monitores em Clubes de Ciências repercutem no desenvolvimento de suas concepções sobre ensino de ciências? O estudo é de natureza qualitativa e do tipo estudo de caso. Os sujeitos de pesquisa são 17 monitores graduandos do curso de Ciências Biológicas de uma universidade situada ao sul do Brasil. Como instrumento de coleta de dados utilizou-se a entrevista semiestruturada, e o material coletado foi analisado por meio da Análise Textual Discursiva (ATD). O produto da análise realizada foi organizado em torno de três categorias: ensino no Clube de Ciências e aprendizagens realizadas pelos futuros professores; estratégias de ensino no Clube de Ciências; e linguagem e aprendizagem no Clube de Ciências. As experiências vividas pelos sujeitos que realizaram monitoria em Clubes de Ciências contribuíram para o aprimoramento da função docente. O envolvimento como monitores em Clubes de Ciências parece ter contribuído para o aprimoramento das concepções sobre o ensino de ciências dos sujeitos da pesquisa.
\end{abstract}

Palavras-chave: Clube de Ciências. Ensino de ciências. Formação de professores.

Abstract: The training of science teachers is a matter that calls for attention. One possible space for the participation of undergraduates in reinvigorated teaching activities is the Science Club, in which students of undergraduate courses can act as monitors of activities proposed to Basic Education 
students. The research problem of this article was: In what way experiences experienced by monitors in science clubs have repercussions in the development of their conceptions on science teaching? The study is qualitative and case study type. The research subjects are 17 graduate monitors of the course of Biological Sciences of a university situated in the south of Brazil. As a data collection instrument, the semi-structured interview was used and the collected material was analyzed through the Discursive Textual Analysis. The product of the analysis was organized around three categories: Teaching in the Science Club and learning by the future teachers; Teaching strategies in the Science Club and Language and learning in the Science Club. The experiences lived by the subjects that carried out monitoring in science clubs contributed to the improvement of the teaching function. The involvement as monitors in science clubs seems to have contributed to the improvement of the conceptions about science education of the subjects of the research.

Keywords: Science club; Science teaching; Teacher training.

Resumen: La formación de profesores de ciencias es un tema que clama por atención. Un espacio posible para la participación de licenciandos en acciones docentes revigorizadas es el Club de Ciencias, en el cual estudiantes de cursos de licenciatura pueden actuar como monitores de actividades propuestas a alumnos de Educación Básica. El problema de investigación del presente artículo fue: ¿De qué forma las experiencias vivenciadas por monitores en clubes de ciencias repercuten en el desarrollo de sus concepciones sobre enseñanza de ciencias? El estudio es de naturaleza cualitativa y del tipo estudio de caso. Los sujetos de investigación son 17 monitores graduandos del curso de Ciencias Biológicas de una universidad situada al sur de Brasil. Como instrumento de recolección de datos se utilizó la entrevista semiestructurada y el material recolectado fue analizado por medio del Análisis textual Discursivo. El producto del análisis realizado fue organizado en torno a tres categorías: Enseñanza en el Club de Ciencias y aprendizajes realizados por los futuros profesores; Estrategias de enseñanza en el Club de Ciencias y Lenguaje y aprendizaje en el Club de Ciencias. Las experiencias vividas por los sujetos que realizaron monitoreo en clubes de ciencias contribuyeron para el perfeccionamiento de la función docente. La participación como monitores en clubes de ciencia parece haber contribuido al perfeccionamiento de las concepciones sobre enseñanza de las ciencias de los sujetos de la investigación.

Palabras clave: Club de ciencias; Enseñanza de las ciencias; Formación de profesores.

\section{Introdução}

A formação de professores de ciências é um assunto que clama por atenção. Docentes tendem a se formar numa perspectiva de ensino transmissivo com foco em conteúdos conceituais. Consequentemente, no momento que iniciam suas práticas escolares organizam as aulas privilegiando a informação científica em detrimento do exercício de reflexão e desenvolvimento de pensamento crítico. Nesse sentido, a formação de professores vai de encontro a concepções contemporâneas que a concebem como um trabalho de reflexividade crítica e (re)construção permanente de práticas (NOVOA, 1992).

Um espaço possível para participação de licenciandos em ações docentes revigoradas é o Clube de Ciências, no qual estudantes de cursos de licenciatura podem atuar como 
monitores de atividades propostas a alunos da Educação Básica. Segundo Albuquerque (2016), tal participação enseja a futuros professores não só a vivência de uma situação real de ensino como também oportunidades para pensar a prática docente, incentivando os acadêmicos a buscarem aprimoramento e a efetuarem mudanças de paradigmas sobre como ensinar ciências. Esse é o tema do presente artigo, que aponta resultados de um estudo cujo problema de pesquisa foi: De que forma experiências vivenciadas por monitores em Clubes de Ciências repercutem no desenvolvimento de suas concepções sobre ensino de ciências?

O texto encontra-se organizado em quatro partes, além da Introdução, na qual se justifica a investigação e se expõe o problema de pesquisa. Na seção Situando teoricamente o tema, é apresentada uma breve reflexão sobre a formação de professores e sobre os Clubes de Ciências, respectivamente. Na seção seguinte, Desenho metodológico do estudo, há informações sobre abordagem e tipo de pesquisa, sujeitos da investigação, instrumentos de coleta de dados e método de análise utilizado. Na penúltima seção, Análise e discussão, apresenta-se o produto da análise realizada em um texto organizado em torno de três categorias: ensino no Clube de Ciências e aprendizagens realizadas pelos futuros professores; estratégias de ensino no Clube de Ciências; e linguagem e aprendizagem no Clube de Ciências. Na última parte, Apontamentos finais, a fim de responder à questão inicial, faz-se uma reflexão sobre como a experiência de monitoria em Clube de Ciências pode contribuir para a futura prática de licenciandos do curso de Ciências Biológicas.

\section{Situando teoricamente o tema}

O acúmulo excessivo de informações e a transmissão de conteúdos têm sido a base da formação de professores de ciências. Além disso, a partir da forte utilização de livros didáticos como principal instrumento de ensino e de currículos engessados, as instituições exigem dos professores aulas com pouca flexibilidade e fundamentadas em assuntos previamente estabelecidos. Dessa forma, docentes elaboram aulas essencialmente conteudistas e, consequentemente, carentes de problemáticas diferenciadas e de situações com potencial para propiciar debate sobre temas contemporâneos. Observando o panorama atual do ensino de ciências, se percebe o conteudismo como característica significativamente presente no cotidiano de professores que, ainda expressando resquícios da sua formação, preocupam-se em vencer conteúdos. Nem sempre a qualidade do ensino e o processo de aprendizagem que envolve o estudante são aspectos sobre os quais o docente reflete e, portanto, as aulas perdem-se em assuntos sem contexto, sem relação com a vida do estudante. 
Visando a contribuir para a formação integral dos estudantes, torna-se necessário que os professores de ciências repensem práticas pedagógicas, exercitando sua autonomia perante a forma de abordar os conteúdos e desenvolver atividades em sala de aula. Imbernón (2009, p.18) diz que "as mudanças sociais orientam-nos o caminho" e que cabe ao professor utilizar o que "é novo e reconstruir sobre o velho". Nessa perspectiva, espera-se que os professores se distanciem dos currículos tradicionais e elaborem novas formas de abordar os conteúdos conceituais a serem estudados, formas essas que possibilitem aos estudantes a compreensão a partir de novas perspectivas e contribuam para atribuição de significados aos conceitos estudados. É nesse cenário que os Clubes de Ciências, vinculados a cursos de licenciatura, apresentam-se como importantes espaços para complementar a formação inicial de professores, posto que essa configuração incentiva os futuros professores a problematizar práticas pedagógicas tradicionalmente estabelecidas, discutindo-as com os demais colegas e, também, com os professores da universidade.

Clubes de Ciências são definidos como espaços pedagógicos com possibilidade de estudos científicos numa perspectiva de construção/produção de conhecimentos, apresentando forte integração com a comunidade e estando seus participantes envolvidos em clima de cooperação e solidariedade. Portanto, torna-se possível planejar, mediar e renovar os conteúdos de acordo com os interesses dos participantes, modificando o significado desse espaço a cada novo encontro (LIMA, 1998; ROSITO, LIMA, 2015). Ainda, as atividades podem tomar como ponto de partida os interesses dos alunos, a busca de conexão com o seu mundo cotidiano, com o intuito de transcendê-lo.

Torna-se difícil caracterizar, de forma padronizada, o funcionamento de um Clube de Ciências, uma vez que ele possui cronograma flexível que pode sofrer qualquer tipo de alteração de acordo com os interesses do grupo. Entretanto, todos os Clubes têm em comum o fato de serem um espaço para os estudantes exporem diferentes interesses científicos, estudarem novos assuntos de acordo com as suas expectativas e praticarem a pesquisa. Neles, cria-se um ambiente impregnado de curiosidade e de interesse. As atividades se realizam de forma coletiva, solidária e participativa, com o envolvimento de colegas e professores nos processos de pesquisa e construção de conhecimentos. Esses princípios convergem para as ideias de Demo (2015), que defende para o contexto educacional o Educar pela Pesquisa:

[...] entra em cena a urgência de promover o processo de pesquisa no aluno, que deixa de ser objeto de ensino, para tornar-se parceiro no trabalho. A relação precisa ser de sujeitos participativos, tomando-se o questionamento reconstrutivo como desafio comum. Sem a intenção de distribuir receitas prontas, que desde logo destruiriam a qualidade 
propedêutica desta proposta, busca-se orientar estratégias que facilitem a capacidade de educar pela pesquisa. (DEMO, 2015, p.2)

Ao mesmo tempo, os princípios presentes nos Clubes de Ciências distanciam-se da transmissão de conteúdos previamente estabelecidos. A vivência em Clubes de Ciências também predispõe os envolvidos - monitores e professores - a estímulos para compreender processos de ensino e de aprendizagem de forma diferenciada e, por decorrência, pensar em possíveis mudanças a serem implementadas não só para o momento de atuação no Clube, mas também em futuras situações de ensino, quando estiverem em sala de aula. Portanto, a participação em Clubes de Ciências enriquece a formação tanto de alunos da Educação Básica como a de futuros professores, acadêmicos que se envolvem nessa atividade. Mancuso et al. (1996) já referiam em suas pesquisas acerca das estruturas de Clubes de Ciências que os professores/monitores, ao se considerarem parte de um grupo de trabalho, encontram nessa organização o amadurecimento profissional e pessoal para estabelecerem um relacionamento de maior intensidade com os alunos, facilitando a troca de aprendizagens.

Portanto, Clubes de Ciências podem oportunizar desenvolvimentos pessoais e profissionais dos monitores atuantes. Por essa razão, a fim de contribuir com a formação de professores e com o panorama geral do ensino científico, destaca-se a importância de compreender as suas concepções sobre como ensinar ciências após a participação em Clubes de Ciências.

\section{Desenho metodológico do estudo}

Este estudo é de natureza qualitativa, pois investiga o fenômeno em seu contexto e pretende "a compreensão dos comportamentos a partir da perspectiva dos sujeitos da investigação" (BOGDAN; BIKLEN, 1994). É ainda uma pesquisa do tipo estudo de caso (YIN, 2005) ao analisar uma instância específica: um Clube de Ciências voltado a estudantes da Educação Básica e mediado por monitores que se encontram em formação inicial de professores. Conforme Yin $(2005$, p.32) “um estudo de caso é uma investigação empírica que investiga um fenômeno contemporâneo dentro de seu contexto da vida real”.

Os pesquisadores responsáveis pela investigação entrevistaram monitores que atuaram em Clubes de Ciências entre 2014-2016. Os sujeitos de pesquisa são 17 monitores graduandos do curso de Ciências Biológicas de uma universidade situada ao sul do Brasil. Nos textos de 
análise, optou-se por identificar os sujeitos da seguinte forma: a letra M significa monitor ou monitora, e os números diferenciam os sujeitos participantes (M1, M2, M3,.., M17).

Como instrumento de coleta de dados utilizou-se a entrevista semiestruturada (FLICK, 2008), constituída por questões parcialmente abertas com a possibilidade de serem livremente respondidas pelo sujeito, buscando melhor expressar o ponto de vista do entrevistado (FLICK, 2008). Os sujeitos foram entrevistados individualmente e seus depoimentos foram gravados em áudio e, logo após, transcritos. O material coletado foi analisado por meio da Análise Textual Discursiva (ATD) proposta por Moraes e Galiazzi (2011). Esse método de análise é utilizado para a descrição e interpretação de informações oriundas de textos como, por exemplo, entrevistas e depoimentos. (MORAES; GALIAZZI, 2011). A ATD é realizada por meio de três etapas principais: unitarização, categorização e comunicação. Da análise do material coletado emergiram três categorias que se encontram desdobradas em subcategorias, conforme é apresentado no Quadro 1.

\section{Quadro 1 - Categorias emergentes a partir da realização da Análise Textual Discursiva}

\begin{tabular}{|c|c|}
\hline Categoria & Subcategoria \\
\hline \multirow{3}{*}{$\begin{array}{l}\text { 1. Ensino no Clube de Ciências e } \\
\text { aprendizagens realizadas pelos futuros } \\
\text { professores }\end{array}$} & 1.1 Planejamento e organização \\
\hline & $\begin{array}{l}1.2 \text { Relação monitor-aluno e } \\
\text { aprendizagem }\end{array}$ \\
\hline & 1.3 Mediação como desafio constante \\
\hline \multirow{2}{*}{$\begin{array}{l}\text { 2. Estratégias de ensino no Clube de } \\
\text { Ciências }\end{array}$} & 2.1 Conciliação entre prática e teoria \\
\hline & $\begin{array}{l}\text { 2.2 Diferentes possibilidades de } \\
\text { estratégias de ensino }\end{array}$ \\
\hline $\begin{array}{l}\text { 3. Linguagem e aprendizagem no Clube } \\
\text { de Ciências }\end{array}$ & \\
\hline
\end{tabular}

Fonte: As autoras (2018)

\section{Análise e discussão}

1. Ensino no Clube de Ciências e aprendizagens realizadas pelos futuros professores

Conforme Albuquerque (2016), participantes de Clubes de Ciências desenvolvem habilidades interpessoais e intrapessoais. Por isso, é possível afirmar que esse ambiente também funciona como espaço para formação de professores na medida em que permite refletir sobre a atuação como docente. A partir das vivências no período de atuação no Clube de Ciências enquanto ensinavam alunos de Educação Básica, os monitores desenvolveram aprendizagens sobre docência com potencial para serem utilizadas em suas futuras práticas. 
São discutidos, nesta categoria, aspectos de planejamento e de organização, aspectos da relação monitor/aluno e da aprendizagem de conteúdos conceituais e aspectos do desafio de mediar aprendizagem e relações entre estudantes.

\subsection{Planejamento e organização}

Esta subcategoria faz referência ao papel do Clube de Ciências no desenvolvimento da habilidade de planejamento e organização de aulas. O planejamento dos encontros configurase como um dos princípios do Clube de Ciências e é vivenciado pelos monitores semana após semana. M15 relata: "[...] nós sempre temos uma hora e meia de Clube então a gente sempre planeja a atividade do dia em cima daquela uma hora e meia, em cima do tempo daquele material que nós vamos ter e previamente outro monitor encaminha, já pede. E a gente sempre fica com uma carta na manga”. O monitor M4 também salienta a importância de eles terem uma atividade pré-elaborada para ser realizada caso sobre algum tempo no encontro do Clube: "Mas nem sempre tem um plano B, tem que ter um plano B. O Clube ajuda nisso." Menegolla e Sant'anna salientam sobre o planejamento de aula:

[...] é um instrumento direcional de todo o processo educacional, pois estabelece e determina as grandes urgências, indica as prioridades básicas, ordena e determina todos os recursos e meios necessários para a consecução de grandes finalidades, metas e objetivos da educação. (MENEGOLLA, SANT'ANNA, 2001, p.40)

Conforme os relatos dos monitores, o Clube de Ciências desenvolve a prática de organizar e planejar com antecedência os encontros e as atividades a serem realizados. Essa habilidade é importante na formação de novos professores, visto que, conforme Luckesi (2014, p. 106), “o ato de planejar, a prática do planejamento em nosso país, especialmente na educação, tem sido conduzida como se fosse uma atividade neutra, sem comprometimentos".

Estudantes de licenciatura com pouca vivência no espaço escolar podem encontrar insegurança para atuar em sala de aula. Nessa perspectiva, o ato de planejar os encontros do Clube auxilia a desenvolver autoconfiança. O monitor M12 aponta: “[...] essa parte de planejamento, de formação da parte de registros: de sentar e colocar no papel, eu tenho ainda essa dificuldade. Mas com o tempo a gente vai aprimorando, e eu já percebi que, aos pouquinhos, para mim já está melhorando. Então o Clube me ajudou bastante”. O monitor M2 acredita que a organização das atividades com antecedência facilitou seu trabalho no Clube: "Eu acho que, assim, com relação ao Clube, [...] ele ajuda muito a você organizar, fazer um planejamento antes". Esse entendimento é confirmado por Castro (2008, p.53) ao 
referir que "o planejamento deve existir para facilitar o trabalho tanto do professor como do aluno. O planejamento deve ser uma organização das ideias e informações". Confirmando o valor do planejamento, Da Silva e Ferreira (2009) mencionam que o planejamento das atividades no Clube de Ciências permite que os estudantes de Educação Básica reconheçam com maior facilidade os fenômenos e conceitos científicos envolvidos nas atividades.

A segurança que os licenciandos sentem quando vão para os encontros com um plano alternativo é uma experiência que pode levar ao reconhecimento do planejamento como ato essencial para a qualidade do ensino e para a aprendizagem, qualquer que seja o espaço do ambiente escolar, incluindo a sala de aula. Entretanto, embora atividades bem planejadas contribuam para aprendizagem, não são suficientes. As interações entre monitores e estudantes também são determinantes nesse processo, como se descreve a seguir.

\subsection{Relação monitor-aluno e aprendizagem}

O desenvolvimento e a compreensão da importância da relação monitor e aluno, ou professor e aluno, para a aprendizagem dos estudantes foi uma percepção recorrente dos monitores. As menções apresentadas a seguir representam a expressão da totalidade dos licenciandos entrevistados. M9 relata que, durante os encontros realizados, foram criados importantes laços entre os estudantes e os monitores: "A gente cria também um vínculo grande com eles e eles gostam bastante da gente”. M10 também observa: "Ah, eles notam a gente o tempo todo. Eles sempre perguntam como é que você está. Esse vínculo é tão bom”. A relação desenvolvida entre os sujeitos é importante para o processo de aprendizagem do estudante, pois, conforme Tassoni (2000), o vínculo afetivo estabelecido é essencial para a aprendizagem:

[...] para a criança, torna-se importante e fundamental o papel do vínculo afetivo, que inicialmente apresenta-se na relação pai-mãe-filho e, muitas vezes, irmão(s). No decorrer do desenvolvimento, os vínculos afetivos vão ampliando-se e a figura do professor surge com grande importância na relação de ensino e aprendizagem, na época escolar. (TASSONI, 2000, p.3)

Numa outra perspectiva, os monitores relataram que, na relação com os alunos, eles mesmos aprendem a efetuar novas conexões entre os conceitos trabalhados, ligações essas que inicialmente não tinham planejado ou pensado. M10 acredita que aprende juntamente com os estudantes: "A gente aprende duas vezes. Aprende quando a gente está preparando e aprende quando está com eles". M8, por sua vez, nota que consegue relacionar novas ideias juntamente com os estudantes: “Às vezes, a gente consegue montar um raciocínio junto com 
eles também. Não sabe, mas consegue, vai conversando, talvez lembrando alguma coisa e já consegue responder à pergunta". Essa relação desenvolvida no Clube de Ciências pode afetar positivamente os monitores nos seus futuros espaços de ensino. M14 afirma que, no Clube de Ciências, existe uma maior integração do que na escola: "Acho que também a parceria, né. A parceria entre o monitor e os alunos porque eu sinto uma diferença no Clube. Chega lá e parece que a gente aprende junto. Trabalhamos juntos, vamos construir juntos. Eu acho que isso a gente leva para a escola depois." A repercussão de um relacionamento interativo entre monitor e aluno é defendida por Da Silva e Navarro (2012, p.97) quando afirmam:

No relacionamento professor-aluno, há trocas de experiências e de conhecimentos, no qual o professor, estando no lugar de que deve ensinar, de transmitir conhecimentos, também aprende com a realidade de cada aluno; e o aluno no lugar de quem recebe ensinamentos também ensina e aprende mesmo sem intencionalidade.

No entanto, é importante lembrar que alunos e monitores apresentam diferentes papéis e funções. Essa percepção foi constatada por M15: “Você consegue ter autoridade o suficiente para sentar ao lado deles; você passa a imagem de que, sim, você é uma autoridade, mas ao mesmo tempo você não é um bicho de sete cabeças." Ao comentar sobre a relação do professor com os alunos, Dos Santos aponta:

[...] como toda relação, também é composta de dois polos - o professor e aluno - e cabe a ambos determinar o clima desta relação. No entanto, [...] cada um desempenha um papel diferente na sala de aula, cabendo ao professor tomar a maior parte das iniciativas, 'dando o tom' para o estabelecimento deste relacionamento. (DOS SANTOS, 2010, p. 72)

O encontro dos monitores de Clubes de Ciências com os alunos de Educação Básica em uma situação real de docência propicia aos licenciandos conscientização sobre as aprendizagens possíveis no que tange aos conhecimentos específicos. Impulsionados pelo desafio de ensinar, ao responder aos questionamentos ou ao participar dos debates, os futuros professores desenvolvem linhas de raciocínio que os auxiliam a realizar uma transposição didática mais qualificada. Ao mesmo tempo, percebem esse movimento como oportunidade para fortalecer sua autoridade nessa relação, atributo esse que é inerente ao papel do professor. Mas a reunião de estudantes e monitores não é isenta de desafios, conforme se apresenta em seguida.

\subsection{Mediação como desafio constante}


Outra percepção captada nos relatos de todos os monitores entrevistados refere-se à insegurança ou ao medo inicial em praticar a docência, tanto com relação à mediação de situações de ensino quanto no que diz respeito a interações entre os estudantes. Esse temor é também encontrado em relatos de diversas outras pesquisas realizadas com estudantes de licenciatura. Por exemplo, no estudo realizado por De Cerqueira et al. (2016) com estudantes de licenciatura de um curso de Ciências Biológicas, os resultados mostram que os licenciandos apresentam insegurança e medo no início do estágio curricular devido à falta de experiência. Na mesma direção, Belusci (2008) aponta que estudantes e futuros professores de ciências podem se sentir rejeitados ou inseguros diante de alunos da Educação Básica. Em contrapartida, o espaço do Clube de Ciências oferece oportunidades para que os futuros professores vivenciem experiências de mediação pedagógica e lidem com suas inseguranças, como observado no relato de M8: "Quando eu entrei na Biologia, eu tinha medo de como seria dar aula. Como eu vou montar uma aula, como que eu vou lidar com as crianças. Mas com o Clube, agora, eu não tenho mais esse medo". O monitor M9 notou uma transformação na maneira de lidar com as inseguranças e na relação com os estudantes: "Também tinha um pouco de medo de dar aula. Pensava: 'Ah, não tem nada a ver comigo', mas eu tenho visto que tem a ver comigo, que eu tenho conseguido lidar com isso, tenho conseguido com que eles me respeitem e aprendam comigo, também”. Monteiro e Teixeira (2016) ressaltam que o professor precisa possuir instrumentos para analisar sua prática docente e também mecanismos de apoio a fim de superar suas dúvidas e inseguranças. Nesse sentido, a escuta, o diálogo que ocorre nas contínuas reuniões entre monitores e professor da universidade, e também com o professor da escola, auxilia na reflexão e na superação de sentimentos pouco positivos concernentes ao encontro com os alunos.

Pelos relatos, é possível compreender que, aos poucos, os monitores foram adquirindo autoconfiança para lidar com os temores iniciais e que se surpreenderam com a modificação de sua autoimagem ao longo dos encontros. M11 relata: “[...] eu sempre tive esse receio de que eu fosse a professora que é a mais odiada da escola, que puxa mais o pé dos alunos. Mas, no Clube, eu exijo deles, mas eles gostam. E isso me surpreendeu.” M7 mudou sua própria perspectiva a partir da reação dos alunos: "Eu tinha medo de ser uma professora chata, distante, os alunos iam perguntar alguma dúvida e eu ia dizer 'Como que tu não sabes isto? E na verdade, não. Eu sou uma pessoa totalmente receptiva para eles”.

No espaço do Clube de Ciências, os monitores também vivenciaram situações de conflito entre os estudantes e, ao longo dos encontros, aprenderam a lidar com circunstâncias adversas. M10, por exemplo, afirma: “[...] são situações que a gente tenta ser moderador. 
Para não excluir ninguém e para fazer todos eles gostarem das atividades que nós estamos fazendo". Vinha e Tognetta (2009) reiteram a necessidade da existência de regras para garantir a harmonia no convívio social.

Panizzi (2004), entretanto, assevera que as relações estão cada vez mais difíceis e conflitantes, levando em consideração que o espaço escolar é constituído de diálogo, interação, conflitos e oposição. Nesse sentido, os monitores relatam ter desenvolvido habilidades para resolver as desavenças vivenciadas nos encontros como, por exemplo, buscar auxílio de colegas ou educadores com maior experiência, conforme expõe M4, que solicitou o auxílio da coordenação e também de professores responsáveis: "Eu sempre procuro a coordenadora, né [...] um aluno ameaçou sair do Clube porque os demais não queriam trabalhar com ele. Sempre que acontece isso, vou lá, falo com a professora responsável, reporto para ela, ela reporta para o professor, e ele vai falar com eles e resolvem o problema”. Nessas situações, o apoio de educadores experientes ou da coordenação escolar é fundamental para auxiliar os monitores e professores iniciantes, tendo em vista que eles ainda não conseguem resolver sozinhos algumas delas. Para Vinha e Tognetta (2009, p.527), “o desenvolvimento da autonomia e de relações mais justas, respeitosas e solidárias são algumas das metas encontradas na maioria dos projetos pedagógicos das instituições escolares".

As ideias trazidas pelos futuros professores sobre planejamento, incertezas e inseguranças para desenvolver situações de ensino e, também, para moderar conflitos entre os estudantes vinculam-se ao conceito de identidade profissional docente. Essa identidade constitui-se pelos significados que o sujeito atribui ao fazer pedagógico, especialmente a partir de relações estabelecidas com os integrantes da comunidade escolar. $\mathrm{O}$ desenvolvimento de atividades docentes no Clube de Ciências propicia aos licenciandos oportunidades para reflexão e para discussão com os pares sobre os acontecimentos vivenciados com os alunos da Educação Básica, num processo contínuo e colaborativo. Tal movimento pode conferir aos acadêmicos uma visão de autoformação como professores de ciências alicerçada no exame reflexivo e crítico das ações desenroladas no espaço de encontro do docente com seus alunos.

\section{Estratégias de ensino no Clube de Ciências}

Nesta categoria, estão reunidas percepções dos entrevistados sobre estratégias de ensino que funcionam no Clube de Ciências e sobre como o uso de procedimentos didáticos ultrapassa a mera utilização técnica. Sobre esse material foi possível estabelecer duas 
subcategorias, uma versando sobre teoria e prática e outra sobre estratégias de ensino, numa visão geral.

\title{
2.1 Conciliação entre prática e teoria
}

Nesta subcategoria, apresentam-se as percepções dos monitores sobre o binômio prática e teoria no Clube de Ciências e em sala de aula. Para Galiazzi et al.(2001) a experimentação, que é uma modalidade de atividade prática, é fundamental no ensino de ciências, convicção corroborada por Krasilchik (2004):

\begin{abstract}
As aulas de laboratório têm um lugar insubstituível nos cursos de Biologia, pois desempenham funções únicas: permitem que os alunos tenham contato direto com os fenômenos, manipulando os materiais e equipamentos e observando organismos. (KRASILCHIK, 2004, p. 86)
\end{abstract}

Os monitores, sujeitos deste estudo, também consideram a atividade prática como uma estratégia importante para estimular o estudante a pensar e para colocá-lo como partícipe de suas aprendizagens, com se percebe no relato de M17: "Eu acho muito melhor você ter uma experiência que faça a criança pensar mesmo, criança de qualquer série, de qualquer ano. Até o terceiro ano do Ensino Médio”. Nessa mesma linha de raciocínio, ao refletir sobre atividades práticas e teóricas, M12, sinalizando a importância de propor atividades diferenciadas, afirma: "[...] algo que faça eles pensar é melhor do que soltar matéria”.

Há consciência de que repassar conteúdo não é papel do Clube de Ciências. Os licenciandos parecem atribuir a esse espaço condições para o desenvolvimento de raciocínio científico por meio de atividades que proporcionem dúvida, vontade de pensar e de encontrar respostas em nível teórico que expliquem as problematizações suscitadas nas atividades. M1 acrescenta um elemento novo a essa ideia ao referir a necessidade de distribuir o tempo destinado ao trabalho com teoria e ao desenvolvimento da prática. Não descuidar do contato com a dimensão teórica encontra-se presente em sua reflexão: "Na minha opinião, a melhor coisa a se fazer em uma aula que eu, particularmente, aprenderia melhor assim, seria misturar as duas, a prática e a teoria".

De outra perspectiva, enfatizando as diferentes formas de aprender e a importância de considerar esse aspecto no momento da escolha de estratégias de ensino do Clube de Ciências, M5 reafirma o papel das atividades práticas: "Eu acho que é preciso colocar uma aula um pouco mais prática, porque às vezes a criança aprende mais vendo, pois tem vários jeitos de 
aprender". O futuro professor ainda continua: “[...] tem crianças que são melhores na prática do que só aula teórica”.

A importância conferida à inserção de práticas e a relação efetuada entre tal inserção e a ocorrência de aprendizagem de conceitos científicos é um aspecto a ser valorizado nos discursos dos licenciandos. Em que pese esse aspecto não ter sido mencionado por todos e tampouco ter havido consenso entre os sujeitos sobre o momento mais adequado para utilizar atividades práticas, as afirmações expõem o entendimento de alguns deles de que somente apresentar a teoria não é suficiente para o aluno aprender. A atividade prática, quando desenvolvida com a teoria, auxilia no processo de aprendizagem do estudante e reitera o caráter de aprendizagem vinculado à atividade experimental, como afirma Krasilchik (2004, p.87) na ponderação a seguir: “[...] qualquer que seja o tipo de exercício, deverá ser seguido de uma discussão geral dos resultados obtidos, para que a atividade não fique reduzida apenas a uma manipulação do equipamento, sem nenhum raciocínio".

Em termos de ordenação, entretanto, exposições teóricas e atividades experimentais podem ser combinadas de diversas formas. M9 relata: “[...] às vezes também a gente faz primeiro a prática e depois a introdução do conteúdo”. Nesse excerto, o futuro professor traz a ideia de que a organização do encontro do Clube, ou de qualquer outra situação de ensino, tem na flexibilidade uma condição primordial. Não há um roteiro a ser seguido. O importante é que se instaure, no espaço de aprendizagem, um diálogo entre elementos da prática e conceitos inerentes ao tema abordado, pois é nesse exercício que os estudantes ampliam e organizam, internamente, os novos conhecimentos com os quais estiveram lidando. Além de atividades experimentais, os licenciandos também mostraram conhecer outras estratégias de ensino. Essa temática é apresentada na próxima subcategoria.

\subsection{Diferentes possibilidades de estratégias de ensino}

Para um grupo de entrevistados, chamou a atenção o uso da estratégia denominada atividade prática. Outro grupo de entrevistados, por sua vez, ateve-se à diversificação de atividades de forma mais geral. Durante o período como monitores do Clube de Ciências, os licenciandos observaram que os encontros apresentam dinamicidade e que, assim como nas aulas em sala de aula, não apresentam a mesma estrutura a cada dia. Para M10, sua experiência no Clube foi importante para descobrir que não existe somente uma maneira de ensinar: "O que a gente percebe é que não existe uma receita de bolo certinha na abordagem prevista”. A realidade dos encontros semanais, nos quais os estudantes de Educação Básica participam com diferentes humores e atitudes a cada dia, fez M10 perceber que não é possível 
propor as situações de ensino sempre da mesma maneira: "[...] às vezes, um dia é um estímulo, eles estão mais estimulados por uma coisa, às vezes é outra. Então a gente tem que aprender a lidar com essas condições adversas que acontecem”. Ao efetuar essa afirmação, M10 denota perceber que para melhor atender às necessidades dos estudantes durante o estudo de um determinado conteúdo o professor pode - e deve - lançar mão de distintos procedimentos didáticos.

Os entrevistados M15, M10 e M1 sugerem a utilização de diferentes estratégias de ensino a fim de modificar a dinâmica da sala de aula. M15 aponta: "Eu acho que quebrar o negócio de quadro, caderno, livro [...] tem tanta coisa que os alunos podem fazer além disso”. M10 afirma: “A gente tem que ver uma maneira de se pôr do lado deles para ver qual abordagem que a gente tem que ter na sala de aula”. M1 tenta se adaptar à maneira como os estudantes agem, aproximando-se deles: "Eu sempre tento ver como que os alunos agem e eu vou agir de acordo com eles". As falas dos participantes dão visibilidade à constatação de que existem muitas estratégias de ensino que podem ser utilizadas pelos professores para constituir a dinâmica das aulas. No entanto, em um nível mais profundo, os licenciandos mostram ter percebido que, além de um bom planejamento, contemplando procedimentos didáticos adequados, é preciso o docente estar atento aos anseios dos estudantes. Nesse sentido, as reflexões dos licenciandos vão ao encontro das ideias de Meirieu (2002), para quem o encontro do professor com seus alunos pode configurar uma relação de parceria ou uma relação de resistência. E, para a ocorrência de aprendizagem, é preciso haver convergência entre o que o professor pretende ensinar e o que o aluno deseja aprender, cabendo ao docente a apresentação de argumentos que favoreçam essa aproximação.

\section{Linguagem e aprendizagem no Clube de Ciências}

A presente categoria reúne aspectos que destacam a importância da linguagem para o processo de aprendizagem dos estudantes. A análise possibilitou compreender que a linguagem utilizada pelos monitores influencia a forma como os alunos aprendem, auxiliando-os no entendimento de diferentes assuntos. Tal construção de conhecimento parece ser mediada pela comunicação diferenciada entre os monitores e a turma.

Sobre esse tema, M12 diz ter constatado que um conceito científico - o qual ele chama de matéria - não compreendido pode ser esclarecido apenas pela modificação de sua linguagem. Em seu depoimento, ele afirma: “[...] às vezes pode ser uma matéria que é difícil de aprender, que nem eu estava comentando oficialmente, mas o assunto surge. Aí já aconteceu de o aluno dizer que não havia entendido nada antes, mas que com o exemplo 
dado, dito da forma como eu falei, fez toda diferença e fez ele entender. Por isso acho essa questão da linguagem é fundamental". De acordo com os entrevistados, utilizar a linguagem informal - aquela falada no cotidiano dos estudantes - auxilia em todo esse processo, conforme pode ser evidenciado nas falas de M6 e M7, respectivamente: "[...] se você aprendeu a linguagem deles, você pode apresentar um slide com a linguagem deles. E aí, muitas vezes, a aula teórica pode ser muito bem recebida"; "[...] eles têm uma linguagem própria, deles como crianças e nós nos distanciamos disto por algum motivo. Acho que não precisava. Então a grande sacada é a gente poder voltar a ter essa comunicação que as crianças têm". O uso de uma linguagem próxima àquela utilizada pelos estudantes é essencial, pois é a partir do diálogo que a aprendizagem pode ocorrer. De acordo com Síveres (2015, p. 27), “[...] o diálogo, como um princípio, está vinculado a uma energia germinadora e potencializadora da condição humana e, portanto, do processo de construção do conhecimento e do percurso educativo". Em outras palavras, em ambientes educativos, a mediação entre os sujeitos aprendentes e o objeto a ser conhecido se dá por meio do diálogo que ocorre entre os estudantes e o professor e dos estudantes entre si.

Os futuros professores que fizeram parte da pesquisa identificaram essa condição de aprendizagem. M12 explicita sua conscientização ao comentar: “[...] achei importante essa questão de ver o diálogo, entender o que eles estão conversando, como é a linguagem deles [...]. Então você vê que muita coisa da linguagem deles é diferente lá e isso fica, apesar de estar sempre mudando. Ano que vem já vai ser uma linguagem um pouquinho diferente. Mas é isso, tem que estar atento ao que eles estão falando agora para depois você poder utilizar isso com eles".

Outros integrantes do grupo, como M14 e M15, corroboram a ideia. M14 aponta: “[...] eles estão em outro mundo, eles não conseguem entender o que é o átomo e o que é a molécula. Mas se eu consigo trazer isso para a vida deles, falando de uma forma que faça parte da realidade deles, faz sentido e eles conseguem aprender”. M15 afirma: "Eles só aprendem quando encontram sentido naquilo. Se não tiver sentido, vai entrar aqui e sair aqui". Os dois depoimentos apresentados expõem outro aspecto relevante do uso da linguagem na sala de aula: a contextualização. Relacionar os novos conceitos científicos com os anteriormente aprendidos e também garantir que eles estejam vinculados ao cotidiano do estudante apresenta-se como uma importante etapa da aprendizagem. Solé (1997), para quem a aprendizagem inicia quando o estudante revisa esquemas de conhecimento anteriormente estabelecidos, refere ser a contextualização a oportunidade de o sujeito aprendente criar um elo entre os conceitos já construídos e as informações novas. É nesse movimento de 
atribuição de novos significados que o sujeito complexifica sua compreensão sobre o objeto de estudo. Reconhece-se, portanto, que a adequação da linguagem pode favorecer a aprendizagem, e o fato de os futuros professores se conscientizarem dessa importância sinaliza uma possível incorporação desse hábito em suas práticas como docentes.

\section{Apontamentos finais}

A pesquisa aqui apresentada investigou concepções dos monitores participantes de um Clube de Ciências, buscando compreender como essas vivências influenciaram suas visões sobre o ensino de ciências. A análise do material coletado permitiu responder à questão de pesquisa previamente formulada: De que forma experiências vivenciadas por monitores em Clubes de Ciências repercutem no desenvolvimento de suas concepções sobre o ensino de ciências?

As experiências vividas pelos sujeitos que realizaram monitoria em Clubes de Ciências contribuíram para o aprimoramento da função docente, especialmente pelo destaque dado à reflexão. Pensar sobre as ações realizadas constou, implicitamente, em comentários dos futuros professores sobre formas de mediar situações de aprendizagem e também de conflito, sobre modos de o professor se relacionar com estudantes da Educação Básica e sobre implicações da linguagem no processo de aprendizagem.

Também é identificado o pensar sobre o fazer pedagógico nos comentários sobre questões práticas, como planejamento de aulas, escolha de estratégias de ensino, acompanhamento da aprendizagem efetuada. A proficiência em quesitos técnicos, mais do que associada à aplicação correta de procedimentos didáticos, está vinculada à capacidade de reconhecer que tais decisões não são tomadas de forma neutra, pois uma mesma estratégia de ensino assume características distintas dependendo das concepções do professor sobre conhecimento, ensino e aprendizagem. É por meio do raciocínio reflexivo que o docente toma contato com suas concepções iniciais e, a partir daí, estuda, debate com colegas, experimenta modelos, a fim de encontrar soluções apropriadas para organizar distintos contextos de ensino.

A consciência e o pensamento crítico sobre esses aspectos influenciam a formação da identidade profissional e é possível que os sujeitos integrantes do estudo aqui relatado tenham compreendido a importância de refletir sobre acontecimentos da prática docente para melhor organizar o complexo e singular encontro do professor com seus alunos, seja esse encontro em que espaço for. Nessa perspectiva, o envolvimento como monitores em Clubes 
de Ciências parece ter contribuído para o aprimoramento das concepções sobre o ensino de ciências dos sujeitos da pesquisa. As considerações dos participantes denotam uma consciência menos ingênua sobre o fazer pedagógico do professor de ciências, acenando possibilidades de mais tarde, quando no exercício da profissão, esses licenciandos serem capazes de implementar mudanças e de desenvolver propostas de ensino de ciências autorais. Em outras palavras, entende-se que as experiências vivenciadas encaminham para a constituição de uma identidade profissional que contemple a capacidade de “elaborar/formular com mão própria, para ser capaz de proposta criativa sempre renovada, unindo teoria e prática", conforme expressado por Demo (2015, p. 59) quando destaca virtudes necessárias ao professor contemporâneo.

\section{REFERÊNCIAS}

ALBUQUERQUE, Nathália Fogaça. Clubes de ciências: contribuições para uma formação contemporânea. 89f. Dissertação (Mestrado em Educação em Ciências e Matemática). Pontifícia Universidade Católica do Rio Grande do Sul, Porto Alegre, 2016. Orientadora Prof ${ }^{a}$. Dr ${ }^{a}$. Valderez Marina do Rosário Lima.

BELUSCI, Heloisa Trenche. Impasses na formação inicial de professores de ciências nas series iniciais. 114f. Dissertação (Mestrado em Educação). Faculdade de Educação. Universidade Estadual de Campinas, São Paulo, 2008. Prof ${ }^{a}$. Dr ${ }^{a}$. Elisabeth Barolli.

BOGDAN, Robert; BIKLEN, Sari. Investigação qualitativa em Educação: uma introdução à teoria e aos métodos. Porto: Porto Editora, 1994.

CASTRO, Patrícia Aparecida Pereira Penkal; TUCUNDUVA, Cristiane Costa; ARNS, Elaine Mandelli. A importância do planejamento das aulas para organização do trabalho do professor em sua prática docente. ATHENA Revista Científica de Educação, v. 10, n. 10, 2008.

DA SILVA, Jeremias Borges; FERREIRA, Christiane Philippini. Clubes de Ciências como ambiente de formação profissional de professores. XVIII Simpósio Nacional de Ensino de Física SNEF. Vitória, ES. 2009.

DA SILVA, Ormenzina Garcia; NAVARRO, Elaine Cristina. A relação professor-aluno no processo ensino-aprendizagem. Revista Eletrônica Interdisciplinar, v. 2, n. 8, 2012.

DE CERQUEIRA, Elizabete Cristina; LEITE, Andrea Vieira; CARVALHO, Flávia Veras Marques. O Estágio como ferramenta motivadora para a carreira docente de licenciandos em Ciências Biológicas. III CONEDU. Congresso Nacional de Educação. 2016.

DEMO, Pedro. Educar pela pesquisa. 10. ed. Campinas: Autores Associados, 2015.

DOS SANTOS, Sandra Carvalho. O processo de ensino-aprendizagem e a relação professoraluno: aplicação dos "sete princípios para a boa prática na educação de Ensino 
Superior". REGE Revista de Gestão, v. 8, n. 1, 2010.

FLICK, Uwe. Introdução à pesquisa qualitativa. Porto Alegre: Artmed, 2008.

GALIAZZI, Maria do Carmo, ROCHA Jusseli Maria de Barros, SCHMITZ Luiz Carlos, SOUZA Moacir Langoni de, GIESTA Sérgio, GONÇALVES Fábio Peres. Objetivos das atividades experimentais no ensino médio: a pesquisa coletiva como modo de formação de professores de ciências. Ciência \& Educação, Bauru, v. 7, n. 2, p. 249-263, 2001.

IMBERNÓN, Francisco. Formação permanente do professorado: novas tendências. São Paulo: Cortez, 2009.

KRASILCHIK, Myriam. Prática de ensino de biologia. São Paulo: Editora da Universidade de São Paulo, 2004.

LIMA, Valderez Marina do Rosário. Clube de Ciências: contribuições à formação do educando. 1998. 206 p. Dissertação (Mestrado em Educação) - Faculdade de Educação, Pontifícia Universidade Católica do Rio Grande do Sul, Porto Alegre, 1998.

LUCKESI, Cipriano Carlos. Avaliação da aprendizagem escolar: estudos e proposições. São Paulo: Cortez, 2014.

MANCUSO, Ronaldo; LIMA, Valderez Marina do Rosário; BANDEIRA, Vera Alfama. Clubes de Ciências: criação, funcionamento, dinamização. Porto Alegre: SE/CECIRS, 1996.

MEIRIEU, Philippe. A pedagogia entre o dizer e o fazer: a coragem de começar. Porto Alegre: Artmed, 2002.

MENEGOLLA, Maximiliano. SANT'ANNA, Ilza Martins. Por que planejar? Como planejar? 10. ed. Petrópolis: Vozes, 2001.

MONTEIRO, Marco Aurélio Alvarenga; TEIXEIRA, Odete Pacubi Baierl. O ensino de física nas séries iniciais do ensino fundamental: um estudo das influências das experiências docentes em sua prática em sala de aula. Investigações em ensino de ciências, v. 9, n. 1, p. 7$25,2016$.

MORAES, Roque; GALIAZZI, Maria do Carmo. Análise textual discursiva. Ijuí: Editora Unijuí, 2011.

NÓVOA, António. Os professores e a sua formação. 1992. Disponível em:

<http://repositorio.ul.pt/bitstream/10451/4758/1/fdp-a-novoa.pdf.>. Acesso em: 15 nov. 2015.

PANIZZI, Conceição Aparecida Fernandes Lima. A relação afetividade-aprendizagem no cotidiano da sala de aula: enfocando situações de conflito. Reunião Anual da ANPED, v. 27, 2004.

ROSITO, Berenice Alvares; LIMA, Valderez. Clube de Ciências: Espaço para produção artística? In: Congresso RedPop 2015 - Arte, Tecnologia Y Ciências. Nuevas Maneras de Conocer, 2015, Medelin. Livro de Memórias RedPop 2015. Medelin: RedPop, 2015. v. 1. p. 1046-1052. 
SOLÉ, Isabel. Disponibilidade para a aprendizagem e sentido da aprendizagem. In: COLL, C. (Org.) O construtivismo na sala de aula. São Paulo: Ática, 1997. p. 29-54.

SÍVERES, Luiz. Encontros e diálogos. Brasília: Líber Livro, 2015.

TASSONI, Elvira Cristina Martins. Afetividade e aprendizagem: a relação professoraluno. Psicologia, análise e crítica da prática educacional. Campinas: ANPED, p. 1-17, 2000.

VINHA, Telma P; TOGNETTA, Luciene Regina P. Construindo a autonomia moral na escola: os conflitos interpessoais e a aprendizagem dos valores. Diálogo Educacional, v. 9, n. 28, 2009.

YIN, Robert K. Estudo de caso: planejamento e métodos / Robert K. Yin; trad. Daniel Grassi - 2.ed. -Porto Alegre : Bookman, 2005.

\section{$\underline{\text { SOBRE OS AUTORES }}$}

\section{Beatriz Garcia Lippert}

Mestranda em Educação em Ciências e Matemática pela Pontifícia Universidade Católica do Rio Grande do Sul (PUCRS). E-mail: beatriz.lippert@ gmail.com

\section{Nathália Fogaça Albuquerque}

Mestranda em Educação em Ciências e Matemática pela Pontifícia Universidade Católica do Rio Grande do Sul (PUCRS). E-mail: nathalia.albuquerque@acad.pucrs.br

\section{Valderez Marina do Rosário Lima}

Doutora em Educação pela Pontifícia Universidade Católica do Rio Grande do Sul (PUCRS). E-mail: valderez.lima@pucrs.br 